\title{
LA CIBERPOLÍTICA DE LOS MOVIMIENTOS SOCIALES EN CHILE: ALGUNAS REFLEXIONES Y EXPERIENCIAS
}

Salvador Millaleo Hernández 


\section{SALVADOR MILLALEO HERNÁNDEZ}

Abogado, Dr. en Sociología, Universidad de Bielefeld (Alemania). Ha sido Research Fellow en la Universidad de Bielefeld. Investigador del Centro de Derechos Informáticos de la Universidad de Chile y profesor de la Universidad Diego Portales. Especialista en Sociología de la Tecnología, Sociología del Derecho, Políticas de la Identidad, Teoría del Derecho y Ciberpolítica. 


\title{
LA CIBERPOLÍTICA DE LOS MOVIMIENTOS SOCIALES EN CHILE: ALGUNAS REFLEXIONES Y EXPERIENCIAS
}

\begin{abstract}
Este ensayo se propone exponer brevemente y de manera exploratoria algunos rasgos del desarrollo de la política virtual o ciberpolítica -la política realizada a través de las tecnologías de la Información (TIC)- de los movimientos sociales en Chile. La perspectiva desde la cual será enfocada la ciberpolítica consiste en la medida en que las manifestaciones de opinión y debate a través de dichas tecnologías contribuyen a transformar las esferas públicas en Chile. En este sentido, las manifestaciones crecientes de las campañas electorales mediante Internet no han sido un componente fundamental en su aporte a los múltiples espacios públicos en Chile, como sí lo han sido la formación de plataformas de deliberación y movilización ciudadanas de movimientos sociales en la red.
\end{abstract}

\section{ESFERAS PÚBLICAS EN CHILE}

Nancy Fraser ha concebido la esfera pública como "el foro de las sociedades modernas donde se lleva a cabo la participación política a través del habla. Es un espacio en que los ciudadanos deliberan sobre problemas comunes, por lo tanto, un espacio institucional de interacción discursiva". Mediante este espacio se diferencian los agentes del Estado, las formaciones de la sociedad civil y los mercados. Dicho espacio de comunicación está constituido por un conjunto de espacios asimétricos donde los ciudadanos construyen discursos políticos que compiten por la hegemonía en la comunicación política. Las esferas públicas en una democracia están sujetas a un pluralismo agónico de la comunidad política, en el cual la competencia entre discursos busca reconfigurar la constitución de esta comunidad, pero sin que ninguna puede hacerlo definitiva y permanentemente.

Se puede afirmar que, con la caída de la dictadura militar, Chile ganó la oportunidad de reconstruir una esfera pública democrática. En efecto, los gobiernos de la Concertación desmontaron un fárrago legislativo de restricciones a la libertad de expresión en los diversos medios de comunicación. Sin embargo, dicha oportunidad debe contarse como, al menos, relativamente perdida, en cuanto se dejaron subsistir un conjunto de reglas que permiten restringir la comunicación política de los ciudadanos y, tanto peor, se consolidaron constelaciones de hechos que imponen severas limitaciones a las comunicaciones políticas de la sociedad, como la concentración en muy pocas manos de los medios más masivos, como la TV, los periódicos y las radios.

Lamentablemente, son dichas condiciones las que han acompañado el proceso de mediatización intensiva que han experimentado las esferas públicas en Chile, en el cual decrece el rol de la prensa escrita y de la movilización política copresencial, apuntando a la búsqueda de información, expresión y difusión de opinión en torno a intereses públicos a través de otros medios más masivos, especialmente la TV. Existe disminución de 
la identificación con los partidos políticos y abandono de las manifestaciones políticas y sociales y de las formas tradicionales de movilización política, según sugiere Marín. La televisión, como lo muestran diversos datos de consumo y de audiencias de medios disponibles, se convirtió en Chile en el medio predominante de información y de expresión de la discusión pública, y de mayor credibilidad para los ciudadanos, transformando las condiciones bajo las cuales las personas participan de la esfera pública.

La medialidad televisiva presenta en Chile numerosos defectos como plataforma de una esfera pública democrática, los que son percibidos por la ciudadanía. Así es como en la VI Encuesta Nacional de Televisión de CNTV solo el 30,9 \% de la muestra consideran a los canales nacionales como los más neutros políticamente en relación a otros medios. El análisis de las representaciones de grupos no dominantes por la TV muestra constantemente como dicho espacio transmite modelos socioculturales que subrepresentan a grupos subalternos. Por ejemplo, según Souza y Oyanedel, en cuanto a lo femenino, se concede a la imagen de la mujer un espacio de participación restringida, reducida principalmente a las dimensiones eróticas y afectivas, en tanto que a los hombres se les concede un espacio mucho más amplio, ligado fundamentalmente a lo profesional. Algo análogo ocurre con pueblos indígenas, vecinos de poblaciones de escasos recursos, poblaciones regionales, estudiantes, jóvenes infractores de la ley y otros ciudadanos marginalizados.

\section{LAS ESFERAS PÚBLICAS VIRTUALES}

Frente al referido contexto, Internet emerge como un medio único de comunicación, que además de asumir a todos los demás como un verdadero hypermedio, es particularmente adecuado para proveer plataformas para debates públicos, que son relativamente espontáneos, flexibles y autogobernados. Dentro de este enfoque, la ciudadanía mediática que proporcionan los nuevos medios de Internet conformaría una plataforma común para los diferentes lugares del compromiso político. Del mismo modo, ella conduce a una expansión de los espacios públicos políticos y crea con facilidad espacios públicos alternativos o contraespacios públicos para actores subalternos.

Diversas investigaciones han procurado establecer las condiciones de constitución de las esferas públicas en las plataformas ofrecidas por la Internet. En esa línea, Lincoln Dahlgren ha establecido seis condiciones principales para que se constituya una genuina esfera pública digital y que pueden ser, a su vez, cumplidas por los espacios virtuales de deliberación: autonomía respecto del Estado y del poder económico; razonamientos antes que simples aseveraciones; reflexividad; toma ideal de roles; sinceridad; y, en último lugar, inclusión discursiva con igualdad. Por su parte, Wilhelm ha indicado cuatro componentes esenciales de una esfera pública virtual, a saber: en primer término, la posesión de recursos antecedentes representados por las destrezas y capacidades necesarias para obtener ciertos objetivos políticos; en segundo lugar, la inclusividad, que significa que todas las personas potencialmente afectadas por una política tengan la oportunidad de expresar sus preferencias e influenciar dicha política; en tercer lugar, la deliberación 
en la cual los interlocutores provean razones para soportar sus argumentos, razones que serán validadas en un espacio público libre de la interferencia de los poderes corporativos o de la manipulación de los poderes políticos; en cuarto término, el diseño, es decir, la arquitectura de una red, cubriendo si dicha arquitectura es interactiva, moderada, segura, no censurada y con suficiente capacidad para fines no económicos.

Parafraseando un acostumbrado estilo, al menos desde los libros de Manuel Castells, Malcolm Gladwell, un columnista del New Yorker, en Octubre de 2010, indicaba: "The world, we are told, is in the midst of a revolution. The new tools of social media have reinvented social activism. With Facebook and Twitter and the like, the traditional relationship between political authority and popular will has been upended, making it easier for the powerless to collaborate, coordinate, and give voice to their concerns" 1 (Gladwell, 2010). Pero, a continuación, limitaba con ironía ese optimismo reciclado sobre Internet al declarar que las protestas políticas recientes en el mundo no se tratan realmente de "revoluciones de Twitter y Facebook", sino de un activismo de alto riesgo que requiere siempre de profundas raíces y lazos comunitarios fuertes que dichas redes sociales no pueden proveer por sí solas. Esta idea la reiteró en febrero de 2011 a propósito de las manifestaciones en Egipto. La verdad es que Gladwell no dijo nada nuevo.

En contraste con los entusiastas de las potencialidades democratizadoras de Internet, los ciberescépticos sugieren que, en la práctica, los usos políticos de las tecnologías de la información fallan en transformar los patrones existentes de participación democrática, e incluso pueden profundizar las brechas de participación cívica entre los que están comprometidos en la acción colectiva y los que permanecen apáticos frente a ella. Margolis y Resnick han indicado que la ciberpolítica no ha logrado hasta ahora establecer intereses de la misma manera que las organizaciones políticas tradicionales, como los partidos políticos, los grupos de interés y los medios de comunicación convencionales. Por otro lado, las corporaciones se instalaron en los espacios de Internet y los han colonizado con sus lógicas de producción y circulación de noticias y entretenimiento, que producen, antes que una política transformadora, una "política usual", convirtiendo a las audiencias en consumidores antes que en productores activos de comunicación. Las mismas formas de participación online parecen inadecuadas para sustituir prácticas de las redes de interacción copresencial en las comunidades locales que se basan fuertemente en la confianza subjetiva y emocional. En definitiva, las divisiones sociales en el acceso y uso de las tecnologías de la información amplificarían el poder de los que son económica y políticamente privilegiados y mejor educados, entrenados y con acceso a las tecnologías de la información, marginalizando aun más a los sectores apáticos y a los grupos vulnerables.

1. "El mundo, nos han contado, está en medio de una revolución. Las nuevas herramientas de los medios sociales han reinventado el activismo social. Con Facebook y Twitter y el me gusta, la relación tradicional entre autoridad política y albedrío popular ha cambiado, haciendo más fácil, para los sin poder, el colaborar, coordinarse y darle voz a sus preocupaciones". Traducción de Danusia Paleczek Alcayaga. (N. del A.) 
La investigación empírica sobre el uso de las tecnologías de la información en las comunicaciones políticas ha arrojado hasta ahora algunas evidencias moderadas pero certeras de las siguientes características de la ciberpolítica, siguiendo a Ward y Vedel. La Internet y las tecnologías de la información incrementan la información disponible, así como las fuentes de esa información tanto a nivel de accesibilidad a los datos como de interacción dinámica con ellos. En segundo lugar, ellas reducen los costos de movilización para los sujetos que no tienen acceso a los medios masivos. La comunicación política de Internet puede desestabilizar los órdenes de la comunicación política y así conducir a ciertas formas de desempoderamiento de las estructuras políticas establecidas, cuando el sistema de medios tradicional es particularmente concentrado y conservador. Tercero, ofrecen un mayor alcance de la discusión y el debate público, en cuanto la ciberpolítica afecta las relaciones de representación, las cuales son transformadas por la pluralización del espacio público cuando los sujetos marginalizados de este se organizan en la forma de espacios públicos alternativos, ganando de esa manera en visibilidad. Cuarto, la Internet apoya la transnacionalización de la esfera pública en el sentido de la superación y cuestionamiento de los marcos de referencia nacional de la comunicación política. Por último, Internet ofrece a los ciudadanos más posibilidades de participación en los procesos de decisión pública mediante los mecanismos de consulta y voto electrónicos, cuando el acceso y uso de las tecnologías de la información están suficientemente difundidos en la sociedad.

Si bien los actores políticos establecidos y las corporaciones económicas se han desplegado para ocupar los espacios abiertos por la participación en Internet, la instauración de los principios de Internet como plataforma que trasunta los procesos tecnológicos de la llamada Web 2.0 -movimiento peer-2-peer, movimiento copyleft y Creative Commons, las comunidades de software libre, los sitios de contenido generado por el usuario y las redes sociales- han traído de vuelta las potencialidades políticas de la web y las expectativas asociadas a ellas. Yochai Benkler propone concebir este cambio como un desplazamiento hacia una esfera pública interconectada de muchas esferas plurales, en el sentido que la Web 2.0 ofrece con claridad plataformas para comprometer la cooperación de los diversos grupos de ciudadanos y proveer opiniones y observaciones diferenciadas. La esfera pública de la Web 2.0 sería más bien una constelación de redes plurales interconectadas antes que un espacio de integración de la sociedad. Ella ha demostrado sus capacidades para generar una multiplicidad de entornos flexibles, alimentados por mecanismos de coordinación de una inteligencia colectiva, donde se puede desenvolver la identidad online de los ciudadanos -la llamada política viral-, y que son sensibles a los valores de autoexpresión emocional mediante formatos audiovisuales.

Sin embargo, subsisten las suspicacias sobre la posibilidad de que la política viral promueva y refuerce las desigualdades tradicionales en la participación política y la influencia en la sociedad debido a las falencias de los nuevos modos de participación que facilitan: espontáneos, individualizados y desorganizados. La política viral puede incrementar el elitismo de la sociedad en cuanto las redes sociales bien conectadas, el conocimiento político y las capacidades técnicas se vuelven más importantes para construir 
campañas efectivas, de manera que se construirían "elites temporales". De acuerdo a Gustafsson: "The political entrepreneurs of a successful campaign of viral politics form, together with temporary supporters of the cause to be found in interconnected social networks, a temporal elite, having the necessary knowledge, skills and (perhaps above all) the motivation to promote the cause."

Las investigaciones actuales se están dedicando principalmente al diagnóstico sobre las esferas públicas virtuales realmente existentes y en qué sentido estas promoverían la inclusión de los ciudadanos, asumiendo que las plataformas online no son por naturaleza más inclusivas que las formas tradicionales de comunicación política. La experiencia acumulada con proyectos de activismo digital, que no han alcanzado la visibilidad o influencia deseadas, están dando origen también a una incipiente reflexión sobre las formas fallidas de ciberpolítica, en las cuales un entorno cultural y político hostil, como en el caso de Rusia y otros países, o bien la debilidad de estrategias de organización comunitaria, han despotenciado iniciativas de activismo digital. ${ }^{3}$ El número de campañas y acciones fracasadas aún sobrepasa al activismo digital efectivo, predominando campañas inefectivas y la percepción, producida por ellas, de que el activismo digital en general es ineficaz. ${ }^{4}$

\section{ALGUNAS EXPERIENCIAS CHILENAS DE CIBERPOLÍTICA QUE HAN SIDO EXITOSAS}

En el caso de Chile, observamos un fuerte y sostenido desarrollo del uso de Internet. Hemos alcanzado globalmente un número de usuarios de la red en torno a 7,3 millo-

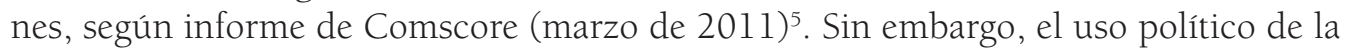
Internet solo recientemente está haciéndose más visible, sobre todo en los últimos tres años, desde las campañas de las últimas elecciones presidenciales y la coordinación de una serie de manifestaciones políticas mediante las redes sociales, como en el caso de las movilizaciones estudiantiles del invierno de 2011. En cualquier caso, hay actores políticos que ya cuentan con una larga experiencia en la política virtual. Hemos querido seleccionar dos casos heterogéneos ${ }^{6}$ de usos exitosos de las tecnologías de la información para la participación ciudadana y la deliberación pública online, para ver

2. "Los pioneros políticos de una campaña exitosa de política viral forman, junto con colaboradores temporales de la causa encontrados en redes sociales interconectadas, una elite temporal, teniendo el conocimiento necesario, capacidades y (quizás sobretodo) la motivación de promover la causa". Traducción de Danusia Paleczek Alcayaga. (N. del A.)

3. Véase: http://www.thewhisper.net/forum/blog.php/2011/03/21/dividing-by-zero-how-activist-movements-break, [consulta: 4 de julio de 2011]

4. Véase: http://www.meta-activism.org/2011/03/failures-in-digital-activism-a-macro-view, [consulta: 12 de mayo de 2011].

5. Véase:http://www.comscore.com/esl/Press_Events/Press_Releases/2011/3/Latin_America_s_Internet_ Population_Grows_15_Percent_in_Past_Year_to_112_Million_People, [consulta: 4 de julio 2011]

6. Los casos más recientes, incluyendo las movilizaciones estudiantiles de 2011 , se han caracterizado por el uso intensivo de las redes sociales. 
cómo las interrelaciones de sus dimensiones tecnológica, social y discursiva permiten entender la medida de los éxitos -éxito entendido en el sentido su visibilidad para la esfera pública hegemónica antes que por logros concretos- de sus comunicaciones políticas.

\section{LA REVOLUCIÓN PINGÜINA DE 2006}

Una de las experiencias más importantes y recordadas de un uso exitoso de las herramientas de la ciberpolítica en Chile consiste en las movilizaciones de los estudiantes durante los meses de mayo y junio de 2006, y que fueron conocidas como "Revolución Pingüina". Entonces se produjeron movilizaciones estudiantiles en diferentes ciudades de Chile, las cuales paralizaron la totalidad de los establecimientos educacionales públicos y que tuvieron una gran adhesión por parte de colegios particulares. Estas protestas tomaron por sorpresa a las autoridades del gobierno y a la oposición. De acuerdo a Victoria Uranga, "fue una movilización que puso en jaque al gobierno y logró instalar el tema de la mala calidad de la educación en la agenda pública. 192 días de marchas, tomas de colegios y protestas diversas visibilizaron a los jóvenes".

La última semana de abril de 2006 comenzaron las primeras movilizaciones estudiantiles que perseguían, en primera instancia, resolver la gratuidad de un pase escolar que además no tuviera restricciones de viajes durante todo el año, así como la gratuidad de la Prueba de Selección Universitaria (PSU). A esas demandas se le sumaron las exigencias de supresión de la jornada escolar completa, de raciones alimenticias para la totalidad de estudiantes de liceos y escuelas públicas, prácticas profesionales remuneradas para los establecimientos técnicos, la derogación del Decreto Supremo 524/1990 que regulaba la conformación de los Centros de Alumnos, la desmunicipalización de la educación y la derogación de la Ley Orgánica Constitucional de Educación (LOCE). Los malos resultados de tratativas con autoridades gubernamentales de entonces generaron un incremento de las movilizaciones en las calles.

El movimiento estudiantil logró, en su punto más alto, la reacción del gobierno. La entonces Presidenta Bachelet intervino en cadena nacional de radio y televisión, avalando las demandas estudiantiles y valorando el clima de efervescencia social. Anunció una "agenda larga" y una "agenda corta" de medidas.

Las movilizaciones de la Revolución Pingüina muestran cómo plataformas tecnológicas se vuelven fundamentales debido antes a la familiaridad con su uso de la generación de adolescentes escolares antes que por una reflexión estratégica, pero que se consolidó de la mano a las necesidades de crear un movimiento social amplio, descentralizado, horizontal y fuerte en las bases, en un contexto de mucha desconfianza respecto de las representación política jerarquizada, tanto en el nivel de la coordinación de la acción colectiva, la comunicación interna del movimiento y la comunicación externa, toda vez que dicho movimiento chocó en un primer momento con la desinformación y manipulación informativa de los medios de masas, hasta llegar a ser reconocido por el mismo Gobierno. 
En cuanto a la dimensión que nos concierne, las tecnologías de la información jugaron sin duda un papel crucial para construir la arquitectura de un movimiento estudiantil nacional. La utilización de la Internet, tanto de las tecnologías Web 1.0 -MSN Messenger, e-mails- como 2.0 -Fotolog, weblogs-, así como de la telefonía móvil permitieron mantener una constante información y realizar comunicaciones internas, incluyendo la comunicación entre estudiantes de la capital con los de regiones, y con la comunidad en general. Gracias a dichos medios, la coordinación de actividades se difundió con mayor facilidad y velocidad.

Las plataformas usadas entonces fueron las siguientes: sitios web de los alumnos de establecimientos secundarios; Weblogs, especialmente Fotologs; MSN Messenger, mediante el cual los dirigentes de cada liceo manejaban bases de datos con listas de cursos completos a los cuales difundían mensajes en forma instantánea; el correo electrónico (e-mail), que sirvió para que los estudiantes de otras regiones intercambiaran documentos referidos a las demandas y leyes, así como para coordinar reuniones de carácter nacional, regional o comunal. Por su parte, la telefonía celular fue la herramienta más utilizada de coordinación. Hubo una importante coordinación de los estudiantes a través de mensajes de texto (SMS), lo cual les permitió a los dirigentes y bases coordinar adecuadamente el movimiento, permitiendo una acción colectiva que logró sorprender a las autoridades y al establishment político, especialmente en el ámbito de las tomas.

Según Ramos y Gerter, los múltiples weblogs fueron creados por colegios; pero estos no alcanzaron gran masificación, puesto que se dirigían principalmente a un público segmentado de cada establecimiento y, por lo tanto, respondían a cuestiones internas de cada colegio. Además, estos sitios, en más de una oportunidad, fueron cerrados y vueltos a abrir, por lo que carecieron de estabilidad informativa, y al final de las movilizaciones muchos fueron definitivamente clausurados. Por otro lado, los fotologs, Principalmente, se constituyeron en la principal herramienta de información de los estudiantes a lo largo del país, mediante el cual los estudiantes de cada establecimiento crearon informaciones alternativas que combatían la desinformación que transmitían los medios masivos tradicionales.

En 2006 ya había entrado fuertemente la red social Flickr en Chile. Como plataforma colaborativa para compartir fotos, Flickr conservó la memoria visual de las distintas escenas de las movilizaciones a lo largo del país. Se destacaron dentro de esa plataforma los grupos Paro Estudiantil / Students Strike. Chile, con más de 500 imágenes; Protestas, marchas, tomas, manifestaciones, con más de 700 imágenes; La Revolución de Los Pingüinos (CHILE), con más de 90 imágenes. También se generó mucho contenido audiovisual por los estudiantes, que fue compartido mediante la plataforma Youtube. En Youtube se difundieron también una serie de entrevistas alternativas, realizadas por los mismos estudiantes, a los dirigentes y voceros del movimiento estudiantil. Para Castellón y Jaramillo, gran parte de las imágenes (videos y fotografías) que fueron exhibidas por los medios tradicionales y que impactaron a la opinión pública, fueron registradas por los mismos estudiantes en las redes sociales audiovisuales citadas. Cada una de las protestas y tomas eran documentadas por los mismos estudiantes mediante cámaras digitales de bajo costo y teléfonos celulares, cuyas imágenes capturadas eran subidas a 
Fotolog y Youtube, o enviadas vía correo electrónico a canales de televisión y la prensa tradicional. Wikipedia significó la posibilidad para los estudiantes de sistematizar rápidamente sus propias acciones y darlas a conocer a la comunidad internacional, quedando registradas ${ }^{\top}$.

En la dimensión social fue precisamente la articulación de la organización de redes descentralizadas de autoorganizaciones de base caracterizadas por la horizontalidad, la que permitió, a la vez que exigió, que las tecnologías jugaran un rol importante en la movilización de los estudiantes de 2006. Junto con ser un movimiento que surgió al margen de los partidos políticos tradicionales y procuró mantenerse al margen de su injerencia, al menos mientras se desarrollaba, los estudiantes construyeron una red basada en la autonomía de grupos de base de cada establecimiento. Estos grupos se autoorganizaban en comités que funcionaban en forma de asamblea, procurando operar de la forma más horizontal posible. Dichas agrupaciones se articularon en la Asamblea Coordinadora de Estudiantes Secundarios (ACES), instancia surgida desde los centros de alumnos y colectivos estudiantiles de los colegios emblemáticos del centro de Santiago y algunos colegios municipales y particulares subvencionados del mismo sector, y que después se transformó en la Asamblea Nacional de Estudiantes Secundarios (ANES). Los colectivos estudiantiles se comunicaban hacia la comunidad mayor principalmente mediante voceros y delegados, no por medio de dirigentes permanentes, sujetos al escrutinio de las asambleas, por lo que, por lo tanto, podían ser removidos en cualquier momento. Los delegados eran los encargados de actualizar y utilizar las plataformas tecnológicas y brindar información a través de ellas y de los medios tradicionales -cosa que se hacía generalmente de noche-. Así, la ANES abrió un Google Group que servía de instancia coordinadora central, aunque nunca se presentó como un sitio oficial.

En la dimensión discursiva fue donde menos relevancia tuvo el uso de la tecnología para el movimiento de los pingüinos. La medialidad de Internet no afectó substancialmente los nodos del discurso de las comunicaciones políticas del movimiento, dirigido estratégicamente a producir una unidad discursiva en medio de las grandes desigualdades entre los públicos convocados por el discurso, de manera que no hay huellas profundas de la tecnología en él, lo que ha permitido caracterizar a su ciberpolítica, al menos en esa dimensión, como episódica. En sus formatos, las comunicaciones electrónicas difundían básicamente, además de la información del movimiento, las escenificaciones de image events diseñados para atraer la atención de los medios tradicionales. En efecto, las entrevistas de la investigaciones posteriores han mostrado que el uso de la tecnología no fue planeada, sino que fue un uso espontáneo de usuarios que ya estaban habituados a ello por otros usos cotidianos, pero sin una reflexión estratégica. La única acción mayor de activismo digital fue la intervención por algunos momentos de la página gubernamental del SIMCE, el 1 de Junio de 2006. De allí que no haya habido innovaciones mayores en el uso político de la tecnología por parte de lo secundarios.

7. Véase: http://es.wikipedia.org/wiki/Movilización_estudiantil_de_2006_en_Chile, [consulta: 4 de julio de 2011] 
Si bien el uso de las tecnologías de la información fue indispensable par los éxitos temporales que alcanzó la Revolución Pingüina, al brindarle un medio para desarrollarse muy rápido -como un flashmob ${ }^{8}$ masivo, por ejemplo-, no alcanzó la profundidad necesaria para generar espacios deliberativos perdurables y tener alcances políticos mayores. De cualquier manera, se trataría solo impropiamente de un movimiento rasante o flashmob, en cuanto el conflicto de la educación es un conflicto histórico de la democracia en Chile en los últimos treinta años. Como experiencia de contraesfera pública virtual, el movimiento pingüino puede con justicia ser caracterizado como incipiente, fragmentario y efímero. En cualquier caso, su mayor virtud fue su impacto nacional, logrando conmover rápidamente a la opinión pública hegemónica y mostrando el poder de Internet para evitar los bloqueos del sistema de medios masivos.

\section{PUNTA DE CHOROS Y BARRANCONES}

En los últimos años el crecimiento de las redes sociales ha redibujado el panorama recientemente descrito. De acuerdo a una encuesta de Comscore y IAB Chile, a noviembre de 2010, el 91 \% de los chilenos conectados a Internet utiliza algún tiempo para redes sociales. ${ }^{9}$

Uno de los acontecimientos que marcó la historia del uso de dichas redes en Chile fue el caso de Punta de Choros. Esta localidad se ubica a corta distancia de las ciudades de Coquimbo y La Serena, en la IV región. Allí se buscaban realizar varios proyectos energéticos que contemplaban la construcción de tres centrales termoeléctricas de la empresa franco-belga GDF Suez Energy: Barrancones, Cruz Grande y Farellones.

Los impactos posibles de esas centrales involucraban poblaciones cercanas, como Totoralillo, La Higuera, Chungungo, Los Choros y Punta de Choros, entre otras. Por otra parte, muy cerca se ubican las reservas marinas de las Islas Choros, Damas, Chañaral y la Reserva Nacional Pingüino de Humboldt, en donde se encuentran más de 800 especies animales y el 70\% son endémicas. En ellas habita el $80 \%$ de la población mundial de pingüinos de Humboldt, una importante colonia de lobos marinos, chungungos, pingüinos magallánicos, yacas y delfines nariz de botella, tortugas marinas, toninas, albatros, cormoranes y el paso de ballenas Fin, Minke y Jorobada, así como el área de manejo y explotación de recursos bentónicos en las caletas de Totoralillo Norte y Chungungo. ${ }^{10}$

El 24 de agosto de 2010, la Comisión Regional del Medio Ambiente (Corema) de la IV región aprobó por 15 votos a favor y 4 en contra el proyecto para construir el proyecto de centrales termoeléctricas a carbón Barrancones en la caleta de Chungungo, al sur

8. El término Flashmob se refiere a la reunión espontánea de muchas personas en un lugar público determinado. (N. del E.)

9. Chile lleva la delantera en redes sociales. Véase: http://www.radiosantiago.cl/columnista.php?cl=1, [consulta: 04 de julio de 2011]

10. En relación a la campaña "Salvemos Punto de Choros", véase: http://www.chaopescao.cl/conflicto. php?tab=punta_de_choros, [consulta: 4 de julio de 2011] 
de Punta de Choros, comuna de La Higuera. Algo interesante de esta medida fue que, durante la campaña electoral presidencial del año anterior, el actual Presidente había prometido no realizar dicho proyecto. En efecto, el Presidente Sebastián Piñera había indicado: "Yo fui a ver ese lugar maravilloso (Punta de Choros). Lo que estamos haciendo es una locura. Yo me voy a oponer a todas las plantas termoeléctricas que atenten gravemente contra la naturaleza y la calidad de vida" ${ }^{11}$.

De manera inmediata, después de la aprobación de Barrancones, miles de chilenos se manifestaron en contra de ella en las redes sociales. El proyecto se había aprobado a las 11:00 de la mañana, y durante las ocho horas siguientes las redes sociales, especialmente Twitter y Facebook, sirvieron de plataforma para manifestar las críticas al proyecto y para la convocatoria a marchas y manifestaciones callejeras a propósito en todo el país. La primera actividad ocurrió en las afueras de la Intendencia de la Región de Coquimbo, apenas minutos después de ser aprobado el proyecto, donde cerca de mil personas manifestaron improvisadamente su rechazo a la central. ${ }^{12}$ Más de 1000 personas se juntaron en la Plaza Sotomayor en Valparaíso y marcharon hasta el Congreso Nacional. ${ }^{13}$ En el centro de Santiago, a las 19:00 hrs. se congregaron más de 3000 manifestantes, incluyendo a algunos parlamentarios y líderes sociales, para protestar contra la central, siendo la manifestación reprimida por la policía bajo pretexto de que la convocatoria no estaba autorizada. ${ }^{14}$

En cuanto a la dimensión tecnológica, en Twitter, la actividad de los críticos de la central discurrió en el hashtag ${ }^{15}$ \#salvemospuntadechoro. El nivel de actividad fue tan alto que el término "termoeléctrica" se convirtió por algunos minutos en un trending topic, es decir, uno de los tópicos más comentados en la red Twitter a nivel mundial. Los usuarios de Facebook también se manifestaron y con casi tres mil seguidores, el grupo "No a las termoeléctricas de la cuarta región" difundió las actividades de protesta y sirvió de portal informativo. También las páginas www.salvemospuntadechoros.org, así como las de Codeff, Océana y Greenpeace, difundían esas informaciones. Junto a ello hay que destacar la campaña audiovisual de Chao Pescao, que explicaremos más adelante.

11. Véase: http://cl.globedia.com/logran-redes-sociales-salvar-reserva-marina-norte-chile, [consulta: 4 de julio de 2011]

12. Punta de Choros: Chilenos acuden a las redes sociales para manifestar su descontento. Véase Emol, Miércoles, 25 de Agosto de 2010, Santiago, Chile, http://www.emol.com/noticias/tecnologia/2010/08/25/432526/punta-de-choros-chilenos-acuden-a-las-redes-sociales-para-manifestar-sudescontento.html, [consulta: 4 de julio de 2011]

13. Véase: http://www.cnnchile.com/ciencia-tecnologia/2010/08/26/miles-de-chilenos-defienden-puntade-choros-en-las-redes-sociales, [consulta: 4 de julio de 2011]

14. Miles llegan a convocatoria flash: Policía reprime con extrema violencia marcha para salvar Punta Choros, The Clinic online, 24 de Agosto de 2010, Santiago, Chile, http://www.theclinic.cl/2010/08/24/ miles-congregados-en-convocatoria-flash-policia-reprime-con-extrema-violencia-marcha-para-salvarpunta-choros, [consulta: 4 de julio de 2011]

15. Los "hashtag" son temas representados a partir de palabras simples, siempre juntas, que los refieran. Van siempre precedidos de un signo "\#", y son usados generalmente en la red social Twitter. Su finalidad es expresar una misma idea en Internet o, en este caso, apoyar una causa específica, atendiendo a la repetición casi simultánea de la misma opinión a nivel público. (N. del E.) 
Además, el miércoles 25 de Agosto de 2010 el grupo Bohemios Hackers Team realizó un defacement de la web de la CONAMA (Comisión Nacional del Medio Ambiente), substituyendo su portada por el video de Chao Pescao. ${ }^{16}$

Se había convocado a otra manifestación masiva el 28 de Agosto, pero el Gobierno anunció que se iba a construir la central en otra parte el día 26 de Agosto. El Presidente Piñera envío un tweet -un mensaje a través de Twitter, que contiene 140 caracteres- señalando: "Hemos logrado una gran solución para proteger santuario naturaleza punta de choros, isla damas y gabiotas (sic), para nuestra y futuras generaciones" ${ }^{17}$.

En la dimensión social, hay que recalcar que, a pesar de la espontaneidad de la actividad de las redes sociales, existieron grupos bastante organizados que desde hace algún tiempo habían estado haciendo críticas y observaciones al proyecto, así como también que las manifestaciones recibieron el apoyo y asistencia de un movimiento ecologista con una larga trayectoria en convocatorias ciudadanas en torno a conflictos ambientales.

Las autoridades de la zona, junto a dirigentes gremiales de los pescadores artesanales, formaron el Movimiento en Defensa del Medioambiente (MODEMA) de la comuna de La Higuera para rechazar la construcción de la central por su impacto medioambiental y en la salud humana de las poblaciones cercanas. Este movimiento estaba vinculado al proyecto de la Corporación Participa Incide/Poder Ciudadano, cofinanciado por la Unión Europea y Open Society Institute para el período 2010-2011, que busca apoyar a diversas organizaciones de la sociedad civil chilena con el fin de fortalecerlas en su derecho de participación ciudadana, especialmente expresado en el de acceso a la información pública. MODEMA venía organizando y realizando una campaña de rechazo a la medida desde hace algún tiempo antes de su aprobación. Ya en 2007, MODEMA se había propuesto como objetivo específico que no se instalaran centrales termoeléctricas en las cercanías de Punta de Choros. Producto de su alianza con el programa Incide de Participa, tuvo una valiosa asesoría para elaborar una estrategia a objeto de impedir la construcción de las centrales. De acuerdo a Andrea Sanhueza, el movimiento desarrolló y fortaleció una estrategia de alianzas, incluyendo, además de Participa, organizaciones sociales como la Asociación Gremial de Pescadores de Punta de Choros, el Sindicato de Pescadores de Caleta Hornos, la Asociación de Regantes de Los Choros, así como al Departamento de Biología Marina de la Universidad Católica del Norte y a organizaciones medioambientales de nivel local, regional y nacional: Línea Verde, Red Ambiental del Norte, Codeff, Green Peace y Fundación Océana, entre otras. Océana fue uno de los grandes voceros y soportes de argumentación en términos científicos del rechazo a las centrales.

El 16 de agosto de 2010, MODEMA había presentado al Presidente una carta con 27.000 firmas adjuntas de apoyo, provenientes de diversos países de Latinoamérica y

16. Chile: hackean página web de la CONAMA en defensa de Punta de Choros. Véase: http://www.pateandopiedras.com/2010/08/chile-hackean-pagina-web-de-la-conama-en-defensa-de-punta-de-choros, [consulta: 4 de julio 2011]

17. Este mensaje fue borrado 10 minutos después, cuando ya era tema. Casa de citas: Piñera sarbó a gabiotas, The Clinic online, 27 de Agosto de 2010, Santiago, Chile, http://www.theclinic.cl/2010/08/27/ casa-de-citas-pinera-sarbo-a-las-gabiotas, [consulta: 4 de julio de 2011] 
Europa, incluyendo Chile, de personas que se oponían a Barrancones. ${ }^{18}$ Posteriormente, habían dado a conocer una lista de irregularidades en el lobby de la empresa citada para conseguir la aprobación del proyecto ${ }^{19}: 1$. Amenazas de muerte de Suez-Energy a dirigentes 2. Cambios sustantivos en las SEREMIS con el nuevo gobierno; 3. La Cámara de Comercio Franco-chilena realizó una invitación a la Alcaldesa y Concejales de la Comuna de La Higuera y Consejeros Regionales a un viaje a Europa a conocer proyectos similares a Barrancones entre el 8 y el 15 de Junio del 2010; 4. La Empresa Suez-Energy presionó a los pescadores para que renuncien a dos áreas de manejo donde físicamente se instalaría la termoeléctrica; 5 . Suez-Energy ha realizado múltiples donaciones a organizaciones de la comunidad; 6. Suez- Energy ofreció capacitación gratuita a la comunidad; 7. Grandes deficiencias en el acceso a la información y a la participación ciudadana en el proyecto Barrancones.

Activistas ecologistas subieron el portal www.salvemospuntadechoros.org y crearon una campaña comunicacional llamada Chao Pescao, con el sitio www.chaopescao. cl, donde se puede aún encontrar una detallada descripción del conflicto. Parte de la campaña fue la creación de un documental y un video en el cual reconocidos actores, periodistas y músicos nacionales manifestaban su rechazo a las centrales termoeléctricas. El video y el documental obtuvieron gran atención mediante las redes sociales y se difundió rápidamente por Youtube, mientras era obviado en los medios tradicionales. Sin embargo, la popularidad de esos materiales audiovisuales en las redes sociales se multiplicó tan rápida y ampliamente que los medios mainstream ${ }^{20}$ terminaron incluyéndolos en sus informativos.

Lucas Zañartu, uno de los líderes de la campaña, indicaba: "No es casualidad que el tema haya explotado con tanta fuerza, y de un momento a otro. Nosotros contactamos a diferentes líderes de opinión en los medios y en internet (sic) para mantenerlos informados sobre lo que estaba ocurriendo en la zona”; "...Y el día en que esto estalló, fue gracias a que muchos estaban al tanto de lo que estaba pasando... eran una 10 mil personas esperando el 'vamos' para salir a la luz, todos de una vez". Ladislao Palma, director de comunicación y creatividad de la campaña, también señaló que "El día de la marcha nuestro sitio web (www.chaopescao.cl) recibió 3 mil visitas por minuto y el video fue visto por un millón de personas en menos de una semana". ${ }^{21}$

Esta campaña más tarde ganó los siguientes premios ${ }^{22}$ : Premio al Aporte Medioambiental 2010 (Fundación Terram); Grand Prix Medios Achap 2010 (Asociación Chilena

18. Véase: http://www.elquintopoder.cl/fdd/web/medio-ambiente/opinion/-/blogs/organizaciones-y-autoridades-en-contra-de-termoelectrica-barrancones [consulta: 04 de julio 2011]

19. Lobby para instalar termoélectrica en Punta Choros: Denuncian larga lista de irregularidades, The Clinic online, 23 de Agosto de 2010, Santiago, Chile, http://www.theclinic.cl/2010/08/23/lobby-parainstalar-termoelectrica-en-punta-choros-denuncian-larga-lista-de-irregularidades [consulta: 4 de julio de 2011]

20. Tendencias aceptadas común y mayormente en la sociedad actual. (N. del E.)

21. El inédito poder de las redes sociales: ¿La nueva forma de presionar?, La Segunda, 3 de Septiembre de 2010, Santiago, Chile, 10.

22. Véase: http://kairosworks.net/575546/Salvemos-Punta-de-Choros [consulta: 4 de julio de 2011] 
de Agencias de Publicidad); Oro Categoría Mejor uso de Medio Ambiente Achap 2010; Oro Categoría Eventos Especiales Achap 2010; Oro Categoría Bien Público Achap 2010; Mejor campaña publicitaria ejecutada en redes sociales Premios WAW 2010

En la dimensión discursiva, pese a la dispersión de la ingente cantidad de comunicaciones políticas que canalizaron en corto tiempo las redes sociales, estas pudieron unificarse en torno a los argumentos y objetivos estratégicos propuestos por quienes encabezaron la campaña.

MODEMA había argumentado que la construcción de las centrales iba a dañar irremediablemente el medioambiente e impactar negativamente en la salud de las comunidades aledañas. A ello también añadió que afectaría el turismo en la zona y que la Subsecretaría de Marina ya había rechazado en dos ocasiones otorgar las concesiones marinas necesarias para ejecutar el proyecto. Así, campaña publicitaria tuvo la capacidad de orientar efectivamente a la opinión pública en la dirección de dichos argumentos, aunque con especial énfasis en los aspectos medioambientales.

El caso del rechazo a Barrancones constituye un éxito no solo en cuanto a sus resultados, sino en cuanto a la visibilidad del movimiento organizado en torno a la campaña. La llamada viralidad, o multiplicación acelerada a través de las redes sociales de ciertas opiniones que se transforman en opiniones dominantes o populares, fue lograda por los críticos de Barrancones gracias a una cuidadosa y planificada campaña, donde existieron asesorías expertas, como en el caso del programa Incide de Participa y un movimiento ecologista de larga trayectoria. La experiencia acumulada por los ecologistas en numerosas movilizaciones ocurridas durante los últimos veinte años en torno a problemas ambientales sirvió para diseñar una campaña eficaz contra las centrales termoeléctricas.

Debe destacarse que el movimiento ecologista tiene una larga trayectoria desde antes de la transición a la democracia, y que muchos de sus líderes ya tenían acceso a las redes sociales y las estaban usando con profusión, al menos desde las campañas electorales del año 2009. Como en el caso de la Revolución Pingüina, el movimiento estuvo dotado de independencia respecto a los actores políticos establecidos, quienes fueron sorprendidos en alguna medida por la dinámica de la protesta. Pero a diferencia del caso anterior, la viralidad de las manifestaciones en las redes sociales avanzó mucho más rápidamente en la percepción del público general que en el caso de las protestas del 2006. En este sentido, la movilización de Barrancones es más puramente un caso de flashmob, pero a nivel cibernético. En cualquier caso, la movilización estudiantil alcanzó proporciones considerablemente mayores que en el caso de Barrancones, donde la movilización, antes que masiva, fue sorpresiva y relativa a un tema que nunca había sido prioritario en las agendas de discusión política en el país.

Debido a la velocidad de la expansión de la protesta y al diseño publicitario de la campaña no puede hablarse fácilmente de la instalación de foros de deliberación, sino más bien de la expansión de emociones colectivas asociadas a problemas públicos y a la falta de transparencia de las autoridades en el tema. 


\section{BALANCE PROVISIONAL}

Estos dos casos, en 2006 y 2010, son ejemplos de la realización de comunicaciones políticas y la búsqueda de objetivos políticos en Internet en el ámbito nacional. Aunque Chile ha liderado sistemáticamente los indicadores de uso de las tecnologías de la información en Latinoamérica, estos casos son relativamente tardíos en relación a otras experiencias en la región y en el resto del mundo. Lo que observaremos probablemente va a ser una multiplicación de estos eventos, aunque no necesariamente con perspectivas de éxito.

El lenguaje y las plataformas electrónicas que proporcionan la Internet y las tecnologías móviles fueron utilizados generosamente, de acuerdo al estado del uso habitual de esas tecnologías en cada uno de los momentos descritos de movilización. Se observa, en el último caso, una planificación significativa que organiza una campaña e integra a las plataformas electrónicas disponibles como parte estratégica dentro de ella, lo cual contrasta con la apropiación espontánea que hizo el movimiento estudiantil del 2006. No se puede descartar que las movilizaciones de 2006 fueron un aprendizaje para lo que ha ocurrido como movilizaciones virtuales a partir de 2010.

En ninguno de ambos casos, las plataformas tecnológicas por sí solas alcanzaron a levantar un movimiento social masivo, sino que se requirieron diversos niveles de organización offline para lograr una movilización virtual. Por otra parte, en ambos casos, los espacios públicos virtuales fueron concebidos como complementarios e instrumentales para ocupar el espacio público que verdaderamente se buscaba ocupar, el cual es el espacio de las calles.

Sin embargo, el punto de partida de ambos movimientos fue el hecho de que a pesar de que los medios tradicionales son organizaciones en principio hostiles a los objetivos públicos que perseguían los movimientos sociales, se consiguió que las plataformas electrónicas sirvieran de contraesferas públicas de información y deliberación. Esto confirma, para el caso de Chile, la perspectiva que atribuye a Internet cierta capacidad para ofrecer oportunidades políticas a los sujetos y discursos excluidos de la esfera pública hegemónica.

Sin duda, la investigación en las ciencias sociales debe documentar y analizar en detalle estos fenómenos y proveer a su interpretación, sin dejarse deslumbrar por el fetichismo o los miedos que la tecnología siempre ha despertado, sino incorporando el contexto general de las estructuras sociales de la sociedad en que estos han ocurrido y seguirán ocurriendo.

\section{REFERENCIAS BIBLIOGRÁFICAS}

Aguilera, O. "Medios de comunicación en Chile, movimientos juveniles y políticas de la visibilidad", en Comunicação, mídia e consume, 5 (14), 2008, págs. 55-68.

Benlker, Y., The Wealth of Networks: How Social Production Transforms Market and Freedom. New Haven: Yale University Press, 2006. 
Bollier, D., Viral spiral, How the Commoners Built a Digital Republic of Their Own, New York/Boston: The New Press, 2008.

Castellón, Lucía y Jaramillo, Oscar, "La producción audiovisual en la apropiación de contenidos del escolar chileno", en Comunicologia - Revista de Comunicação e Epistemologia da Universidade Católica de Brasilia, 1(7), 2010, págs. 109-121.

Chatterjee, P., La Nación en Tiempos Heterogéneo, Lima: Clacso, 2007.

Coleman, Stephen y Blumer, Jay, The Internet and Democratic Citizenship: Theory, Practice and Policy. Cambridge: Cambridge University Press, 2010.

Coleman, Stephen y Ross, Karen. The Media and the Public, "Them" and "Us" in Media Discourse. Chichester: Wiley-Blackwell, 2010.

Condeza, A., "Las estrategias de comunicación utilizadas por los estudiantes", en Cuadernos de Información, 94, 2009, págs. 67-78.

Dahlberg, L., The Internet and Democratic Discourse: Exploring the Prospects of Online Deliberative Forums Extending the Public Sphere, en Information Communication and Society, 4(1), 2001, págs. 615-633.

Dahlberg, L., "The Corporate Colonization of Online Attention and the Marginalization of Critical Communication?”, en Journal of Communication Inquirí, 29(2), 2005, págs. 1-21.

Dahlberg, Lincoln y Siapera, Eugenia. Radical Democracy and the Internet, Interrogating Theory and Practice, New York: Palgrave Macmillan, 2007.

Davies, Todd y Peña Gandadharan, Seeta. On line Deliberation, Design, Research, and Practice. Chicago: CSLI Publications/University of Chicago Press, 2009.

Equipo de Culturas Juveniles CESC, La Rebelión del Coro. Análisis de las movilizaciones de los estudiantes secundarios, 2008, véase: http://www.generacion80.cl/documentos/docs/La_rebelion_del_coro.pdf, [consulta: 4 de julio de 2011].

Fraser, N., "Pensando de nuevo la esfera pública, Una contribución a la crítica de las democracias existentes", en Iustitia Interrupta, Reflexiones críticas desde la posición "postsocialista", Bogotá: Siglo del Hombre / Universidad de Los Andes, 1997, Págs. 95-133.

Fraser, N., "Transnationalizing Public Sphere", en Theory, Culture E Society, 24 (4), 2007, págs. 7-30. Gladwell, M., Small Change, Why the revolution will not be tweeted, New Yorker, octubre 42010 , véase: http://www.newyorker.com/reporting/2010/10/04/101004fa_fact_gladwell [consulta: 4 de Julio de 2011].

González, Juan; Cornejo, Rodrigo; Sánchez, Rodrigo, "Estamos dando clases: Significados y perspectivas del movimiento nacional de estudiantes en Chile", en Boletín Referencias 19, año 3, Foro Latinoamericano de Políticas Educativas FLAPE, 2006, véase: http://movimientoestudianteschile.blogspot.com/2006_07_01_archive.html, [consulta: 4 de julio de 2011].

Gripsrud, J., "Digitising The Public Sphere: Two Key Issues", en Javnost-The Public, 16(1), 2009, págs. 5-16.

Gustafsson, N., "This Time It's Personal: Social Networks, Viral Politics and Identity Management”, en Riha, Daniel y Maj, Anna (Eds.), Emerging Practices in Social Networking and Cybercultures, Amsterdam/New York: Rodopi, 2010, págs. 35-44.

Jiménez, César y Muñoz, Jorge, "Estructura de los medios de comunicación en Chile", en Razón y Palabra, No. 60, 2011, véase: http://www.razonypalabra.org.mx/anteriores/n60/varia/jimenes_munoz.html.

Margolis, Michael y Resnick, David, Politics as Usual: The Cyberspace 'Revolution, Thousand Oaks, CA.: Sage, 2000.

Margolis, Michael y Resnick, David, "Waiting for Cyber-Democracy is like waiting for Godot", en HARPER, Joseph; Yantek, Thom (Eds.), Media, Profit, and Politics, Kent, Ohio: Kent University Press, 2003, págs. 232-248. 
Martín, C. "Televisión y transformaciones de la esfera pública", en SECRETARÍA DE COMUNICACIONES. La función politica de la televisión, tendencias, contenidos y desafíos en el Chile de hoy, Santiago de Chile: Ministerio Secretaría General de Gobierno, Gobierno de Chile, 2007, págs 41-54.

MODEMA, Proyecto Barrancones no tiene piso, 4 Razones, Declaración Pública, agosto de 2010, véase: http://www.participa.cl/wp-content/uploads/2010/07/Declaración-Pública-actualizada-2-8-2010.pdf, [consulta: 4 de julio de 2011]

Mouffe, C., "Which public sphere for a democratic society", en Theoria, 49 (99), 2002, págs. 55-65.

Niedermaier, H., "Können interaktive Medien Öffentlichkeit herstellen? Zum Potenzial öffentlicher Kooperation im Internet", en STEGBAUER, Christian y Jäckel, Michael (Eds.), Social Software: Formen der Kooperation in computerbasierten Netzwerken, Wiesbaden: VS Verlag für Sozialwissenschaften, 2008, págs. 49-70.

Putnam, R., Bowling Alone: The Collapse and Revival of American Community, New York: Simon \& Schuster, 2000.

Ramos, Catalina y Gerter, Diego, Revolución Pingüina: Caracterización del caso y descripción de los usos dados a las Tecnologías de la Información y Comunicación. Tesis para optar al título de Periodista y al grado de Licenciado en Comunicación Social, Valdivia: Universidad Austral de Chile, 2008.

Rasmussen, T., "The Internet and Differentiation in the Political Public Sphere", en Nordicom review: Nordic research on media \& communication, 29 (2), 2008, págs. 73-84, véase: http:// dialnet.unirioja.es/servlet/revista?codigo $=15028$

Rheingold, H., Smart Mobs: The next social revolution, New York: Basic Books, 2003.

Rheingold, H., "Mobile Media and Political Collective Action", en Rheingold, Howard y Katz, James (Eds.), Handbook of mobile communication studies, Boston: The MIT Press, 2008, págs. 225-240.

Sanhueza, A., Caso Barrancones. Un ejemplo de incidencia política, 11 de noviembre de 2010, véase: http://www.incide.cl/11/11/2010/caso-barrancones-un-ejemplo-de-incidencia-politica [consulta: 4 de julio de 2011]

Shane, P., "Introduction: The Prospects for Electronic Democracy", en Shane P. (Ed.), Democracy on line. The Prospects for Political Renewal through the Internet, New York/London: Routledge, 2005.

Sierra, L,. "La transición y la esfera pública", en Persona y Sociedad, XVIII (2), 2004, págs. 113120.

Uranga, V., "Las nuevas batallas de Chile", en Rabinovich, Eleonora; Magrini, Ana; Rincón, Omar (Eds.), en "Vamos a portarnos mal" [Protesta social y libertad de expresión en América Latina], Bogotá: Friedrich Ebert Stiftung, 2011, págs. 77-88.

Whal-Jorgensen, K. (Ed.), Mediated Citizenship, London/New York: Routledge, 2008.

Ward, Stephen y Vedel, Thierry, "Introduction: The potential of Internet revisited", en Parliamentary Affairs, 59(2), 2006, págs. 210-225.

Wilhelm, A., Democracy in the digital Age, challenges to political life in cyberspace, New York/London: Routledge, 2000.

Wimmer, J., (Gegen-)Öffentlichkeit in der Mediengesellschaft, Analysen eines medialen Spannungsverhältnisses, Wiesbaden: VS Verlag für Sozialwissenschaften, 2007.

Wolf, A., Articulating a Movement: A Discourse Analysis of the Pingüino Student Movement in Chile, 2009, véase: http://dspace.wrlc.org/handle/1961/7897, [consulta: 4 de julio de 2011]. 